\title{
Care of the liver transplant patient
}

\author{
Mamatha Bhat MD FRCPC ${ }^{1}$, Said A Al-Busafi MD FRCPC ${ }^{1,2}$, Marc Deschênes MD FRCPC ${ }^{1}$, Peter Ghali MD FRCPC
}

\author{
M Bhat, SA Al-Busafi, M Deschênes, P Ghali. Care of the liver \\ transplant patient. Can J Gastroenterol Hepatol 2014;28(4):213- \\ 219.
}

OBJECTIVE: To provide an approach to the care of liver transplant (LT) patients, a growing patient population with unique needs.

METHODS: A literature search of PubMed for guidelines and review articles using the keywords "liver transplantation", "long term complications" and "medical management" was conducted, resulting in 77 articles.

RESULTS: As a result of being on immunosuppression, LT recipients are at increased risk of infections and must be screened regularly for metabolic complications and malignancies.

DISCUSSION: Although immunosuppression is key to maintaining allograft health after transplantation, it comes with its own set of medical issues to follow. Physicians following LT recipients must be aware of the greater risk for hypertension, diabetes, dyslipidemia, renal failure, metabolic bone disease and malignancies in these patients, all of whom require regular monitoring and screening. Vaccination, quality of life, sexual function and pregnancy must be specifically addressed in transplant patients.

Key Words: Liver transplant; Long-term complications; Medical management

Since the 1960s, LT has offered a new lease on life to many patients $\checkmark$ with end-stage liver disease (ESLD) and acute liver failure (1). Survival after transplantation has continued to improve over time, with fine-tuned immunosuppression, postoperative care and management of infections. In 2011, 485 LTs were performed in Canada, with 4419 performed over the 10-year period between 2002 and 2011 (2). The one-year survival rate is as high as $85 \%$, while 10 -year survival rates approach $65 \%$ (3). The longer-term survival of LT recipients means that gastroenterologists and primary care physicians are caring for these patients concurrently with transplant specialists. The management of this patient population is both unique and complex. The gastroenterologist must be aware of the specialized needs of LT recipients, and be able to recognize and optimally manage key complications. In the present article, we provide an overview of issues pertinent to the management of LT recipients, principally based on consensus recommendations in the literature.

\section{INFORMATION SOURCES}

The PubMed database was searched using the keywords "liver transplantation", "long term complications" and "medical management", resulting in 77 review articles and guidelines. The Canadian Organ Replacement Register report was a source of information for LT in the Canadian context (2). The Cochrane collaboration website was consulted using the search term "liver transplantation". There were systematic reviews on infectious prophylaxis and quality of life after LT (Level I evidence). The recommendations in the present review are,

\section{Les soins du greffé du foie}

OBJECTIF : Proposer une approche aux soins des greffés du foie, une population croissante de patients aux besoins uniques.

MÉTHODOLOGIE : Les auteurs ont effectué une recherche dans les publications de PubMed et en ont extrait 77 lignes directrices et articles d'analyse à l'aide des mots-clés liver transplantation, long term complications et medical management.

RÉSULTATS : Parce qu'ils prennent des immunosuppresseurs, les greffés du foie sont plus vulnérables aux infections et doivent subir un dépistage régulier de complications métaboliques et de cancer.

EXPOSÉ : Même si l'immunosuppression est essentielle pour maintenir la santé de l'allogreffe après la transplantation, elle entraîne ses propres problèmes médicaux, qu'il faut garder à l'œil. Les médecins qui suivent des greffés du foie doivent savoir que ces patients sont plus vulnérables à l'hypertension, au diabète, à la dyslipidémie, à l'insuffisance rénale, aux maladies métaboliques osseuses et aux cancers, qui exigent tous une surveillance et un dépistage réguliers. Il faut absolument parler aux greffés de vaccination, de qualité de vie, de fonction sexuelle et de grossesse.

\footnotetext{
${ }^{1}$ Division of Gastroenterology and Hepatology, Department of Medicine, McGill University Health Centre, Montreal, Canada; ${ }^{2}$ Division of Gastroenterology, Sultan Qaboos University, Oman

Correspondence: Dr Mamatha Bhat, 687 Pine Avenue West, Montreal, Quebec H3A 1A1. Telephone 514-843-1616, fax 514-843-1421, e-mail mamatha.bhat@mcgill.ca

therefore, based on data from retrospective studies, case series (Level II) or expert consensus guidelines (Level III).

ESLD is the indication for $92 \%$ of LTs, with hepatitis C and alcoholic cirrhosis being the most common etiologies. Fulminant liver failure, mostly due to acetaminophen poisoning, autoimmune hepatitis or viral etiologies, was the indication for $4 \%$ of LTs. LT can be curative for hepatocellular carcinoma (HCC), and was the indication for $15.3 \%$ of LTs between 2002 and 2011 in Canada (2). Advanced, uncorrectable cardiopulmonary disease is an absolute contraindication to transplantation, while age, per se, is not.

\section{IMMUNOSUPPRESSION}

Following LT, immunosuppressants are started and the recipient is monitored closely to prevent organ rejection. Calcineurin inhibitors (CNIs), antimetabolites and corticosteroids are the main categories of available immunosuppressants (Table 1). Most LT centres in Canada choose to administer a combination of low-dose tacrolimus and mycophenolate mofetil (MMF) with or without concomitant glucocorticoids (4). Satisfactory immunosuppression can be achieved with monotherapy in many patients beyond six to 12 months posttransplantation, usually with a CNI alone.

\section{EARLY COMPLICATIONS}

Liver graft dysfunction is a serious complication that can result in loss of the donor organ. The most common presentation is an asymptomatic elevation of liver enzyme levels (Figures 1 and 2). Causes of early 
TABLE 1

Liver transplant medications, adverse effects and monitoring parameters

\begin{tabular}{|c|c|c|c|}
\hline Immunosuppressant & Mechanism of action & Adverse effects & Monitoring parameters \\
\hline Prednisone & $\begin{array}{l}\text { Inhibits leukocyte, macrophage and } \\
\text { T cell activity } \\
\text { Decrease cytokines, prostaglandins } \\
\text { and leukotrienes }\end{array}$ & $\begin{array}{l}\text { Hyperglycemia, hypertension, } \\
\text { dyslipidemia, infectious risk, } \\
\text { osteoporosis }\end{array}$ & $\begin{array}{l}\text { Blood pressure measurement } \\
\text { Monitor glucose, lipids profiles, regular bone mineral } \\
\text { density scan }\end{array}$ \\
\hline Tacrolimus & $\begin{array}{l}\text { Calcineurin inhibitor, prevents T cell } \\
\text { activation }\end{array}$ & $\begin{array}{l}\text { Renal failure, diabetes, hypertension, } \\
\text { neuropathy, dyslipidemia }\end{array}$ & $\begin{array}{l}\text { Blood pressure measurement, monitor glucose, lipids } \\
\text { profiles, renal function, magnesium level, drug level }\end{array}$ \\
\hline Cyclosporine & $\begin{array}{l}\text { Calcineurin inhibitor, prevents } \mathrm{T} \text { cell } \\
\text { activation }\end{array}$ & $\begin{array}{l}\text { Renal failure, diabetes, hypertension, } \\
\text { neuropathy, dyslipidemia, hirsutism }\end{array}$ & $\begin{array}{l}\text { Blood pressure measurement, monitor glucose, lipids } \\
\text { profiles, renal function, magnesium level, drug level }\end{array}$ \\
\hline Mycophenolate mofetil & Inhibits $\mathrm{T}$ cell and B cell proliferation & $\begin{array}{l}\text { Bone marrow suppression with } \\
\text { cytopenias, gastrointestinal side effects }\end{array}$ & $\begin{array}{l}\text { CBC, liver and renal profile, contraindicated in } \\
\text { pregnancy (fetal malformations, first trimester fetal } \\
\text { loss) }\end{array}$ \\
\hline Azathioprine & $\begin{array}{l}\text { Purine analogue, impedes DNA and } \\
\text { RNA synthesis }\end{array}$ & $\begin{array}{l}\text { Bone marrow suppression with } \\
\text { cytopenias, pancreatitis }\end{array}$ & $\mathrm{CBC}$, thiopurine methyltransferase, liver profile \\
\hline Sirolimus (rapamycin) & mTOR inhibitor & $\begin{array}{l}\text { Hepatic artery thrombosis, impair wound } \\
\text { healing, interstitial lung disease, edema, } \\
\text { cytopenias, hyperlipidemia, proteinuria }\end{array}$ & $\begin{array}{l}\mathrm{CBC} \text {, lipid profile, liver profile, contraindicated in } \\
\text { pregnancy due to teratogenicity }\end{array}$ \\
\hline
\end{tabular}

CBC Complete blood count; mTOR Mammalian target of rapamycin

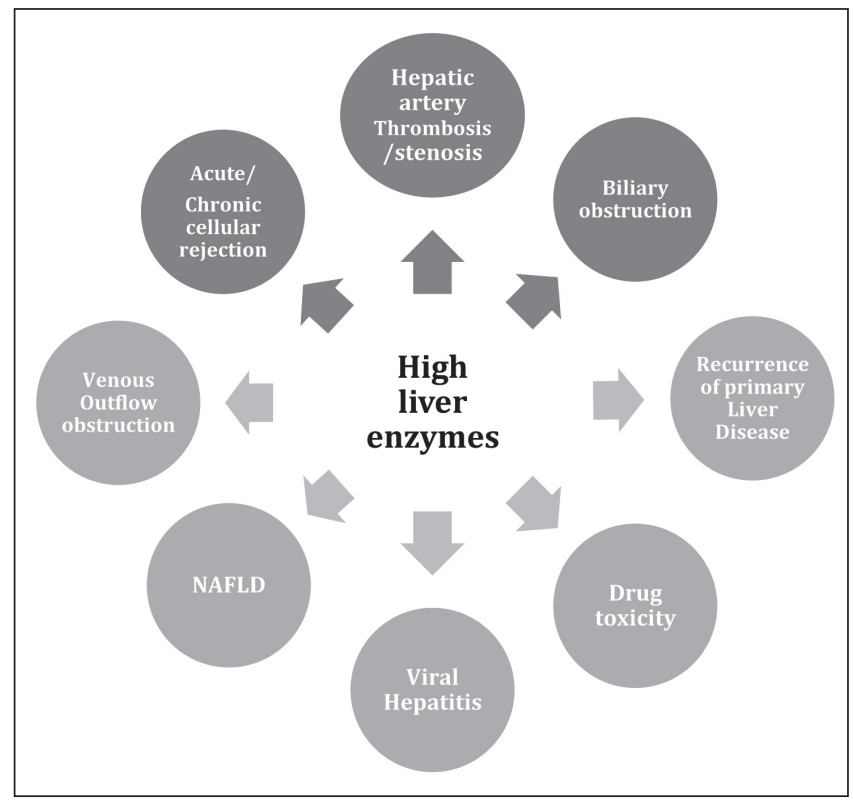

Figure 1) Differential diagnosis of high liver enzyme levels in patients with liver transplant (darker circles indicate early post-liver transplant complications). NAFLD Nonalcoholic fatty liver disease

liver allograft dysfunction are listed in Table 2, with acute cellular rejection being the most common. Salvage of the organ depends on accurate diagnosis and prompt treatment.

Post-transplant infections may develop in up to $20 \%$ of LT recipients during the first month after transplantation. Prophylaxis against infections is, therefore, routinely given to patients for at least six months after LT. A Cochrane review has proven the benefit of fluconazole as an antifungal agent in LT (5), and that of antivirals to prevent cytomegalovirus infection in all organ transplants (6). Trimethoprimsulfamethoxazole is also given to prevent Pneumocystis jirovecii infection.

\section{Recurrent disease following LT}

Recurrent disease after LT is a concern, particularly when the indication for transplant was hepatitis $\mathrm{C}$ virus $(\mathrm{HCV})$ infection or liver malignancies. Details regarding incidence, diagnosis and management are presented in Table 3. HCV infection recurs in virtually all patients in the long term, with development of cirrhosis in $30 \%$ of patients

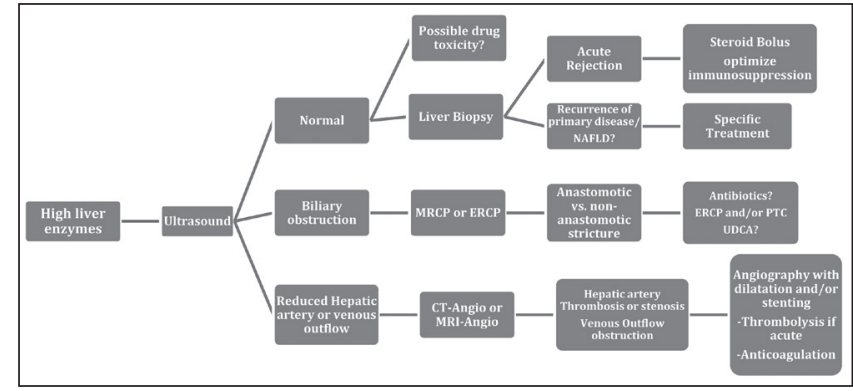

Figure 2) Suggested diagnostic algorithm for liver transplant recipients with high liver enzyme levels. Angio Angiography; CT Computed tomography; ERCP Endoscopic retrograde cholangiopancreatography; MRCP Magnetic resonance cholangiopancreatography; MRI Magnetic resonance imaging; NAFLD Nonalcoholic fatty liver disease; PTC Percutaneous transhepatic cholangiography; UDCA Ursodeoxycholic acid

over five years after LT (7). Protease inhibitors, such as boceprevir or telaprevir, have been used in combination with pegylated interferon and ribavirin in recent years, with sustained virological response of up to $51 \%$ at 12 weeks in the LT population with genotype $1 \mathrm{HCV}$ infection (8). Next-generation protease inhibitors promise to improve on these outcomes even further (9). However, this has required a difficult balancing act with $\mathrm{CNIs}$, given that they are all metabolized by the same cytochrome p450 3A4 enzyme. With the advent of polymerase inhibitors, such as sofosbuvir, with excellent cure rates and no drug-drug interactions with CNIs, treatment of HCV infection in the future will be significantly more easily managed both pre- and post-LT (10).

In the early years of LT, transplantation for hepatitis B virus (HBV) infection was regarded with trepidation. However, since the advent of hepatitis B immunoglobulin and nucleoside/nucleotide analogues, recurrence of disease has not been an issue (11). Future developments are likely to include the incorporation of more effective nucleoside/nucleotide analogues as prophylaxis against recurrence. This will enable us to forego the use of hepatitis $B$ immunoglobulin, especially given that it is a pooled product that carries risk of virus transmission.

With HCC and cholangiocarcinoma, there are concerns for recurrent disease, especially if bulky disease is present on the explant (12). Furthermore, many groups are 'pushing the envelope' with acceptance of HCCs beyond the Milan criteria. Reducing recurrence may include switching to mammalian target of rapamycin (mTOR) inhibitor-based (ie, sirolimus) (13) or neoadjuvant therapies such as sorafenib (14). 
TABLE 2

Causes of early liver allograft dysfunction: Incidence, risk factors, diagnosis and management

\begin{tabular}{|c|c|c|c|c|}
\hline Cause & Incidence & Risk factors & Diagnosis & Management \\
\hline $\begin{array}{l}\text { Primary } \\
\text { nonfunction }\end{array}$ & $5.8 \%$ & Donor age, severity of illness in recipient & $\begin{array}{l}\text { Graft loss, death within } \\
\text { first } 14 \text { days after LT }\end{array}$ & Retransplantation \\
\hline \multirow{4}{*}{$\begin{array}{l}\text { Acute cellular } \\
\text { rejection }\end{array}$} & \multirow{4}{*}{$\begin{array}{l}30 \% \text { to } 50 \% \text { of } \mathrm{LT} \\
\text { recipients }\end{array}$} & Inadequate immunosuppression & \multirow[t]{3}{*}{ Liver biopsy } & Steroid bolus \\
\hline & & \multirow{3}{*}{$\begin{array}{l}\text { Treatment with immune-activating drugs (eg, } \\
\text { interferon in HCV infection) } \\
\text { History of autoimmune liver disease }\end{array}$} & & Conversion to tacrolimus-based regimen \\
\hline & & & & Thymoglobulin \\
\hline & & & & \\
\hline
\end{tabular}

$\begin{array}{cc}\text { Chronic rejection } \quad \begin{array}{l}15 \% \text { with cyclosporine } \\ \text { and } 5 \% \text { with tacrolimus for primary sclerosing cholangitis or } \\ \text { based regimens }\end{array} & \end{array}$

HAT and stenosis $5 \%$ to $10 \%$ of LT Technical difficulties recipients CT angiography

Liver biopsy Increase CNI levels or add sirolimus

Retransplantation (approximately 15\%)

Doppler ultrasound MRI or Thrombectomy, surgical repair, CT angiography retransplantation in the case of HAT, stenting or balloon dilation of the artery for hepatic artery stenosis

Biliary complications (bile leaks and strictures)

$5 \%$ to $15 \%$ ( $15 \%$ to $30 \%$ Prolonged organ ischemia, HAT, donor in living donor LT) organs obtained after cardiac death, CMV infection, immunological rejection, and recurrence of primary sclerosing cholangitis

CMV infection
Ultrasound, MRCP, ERCP, Percutaneous drainage, percutaneous liver biopsy transhepatic cholangiogram, biliary endoscopy, surgery or retransplantation

$\begin{array}{ll}25 \% \text { to } 85 \%, \text { typically } & \text { Donor or recipient is CMV positive before LT } \\ \begin{array}{ll}\text { occurs } 1 \text { to } 4 \text { months } & \text { Over immunosuppression } \\ \text { post-LT } & \text { Noncompliance with prophylaxis }\end{array}\end{array}$
CMV PCR and/or CMV Prophylaxis with valganciclovir and antigenemia or tissue treatment with ganciclovir samples (intestines or liver)

Adapted from references 54 and 55. CMV Cytomegalovirus; CNI Calcineurin inhibitor; CT Computed tomography; ERCP Endoscopic retrograde cholangiopancreatography; HAT Hepatic artery thrombosis; HCV Hepatitis C virus; LT Liver transplantation; MRCP Magnetic resonance cholangiopancreatography; MRI Magnetic resonace imaging; PCR Polymerase chain reaction

TABLE 3

Diagnosis, prevention and management of recurrent liver diseases post-liver transplantation (LT)

\begin{tabular}{|c|c|c|c|c|}
\hline Disease & $\begin{array}{l}\text { Probability of recurrence } \\
\text { (reference) }\end{array}$ & Diagnosis & Prevention & Management \\
\hline HCV infection & $60 \%$ to $90 \%(3)$ & HCV PCR; liver biopsy & $\begin{array}{l}\text { Pre-LT ribavirin + peginterferon + } \\
\text { protease Inhibitors; pre-LT } \\
\text { polymerase inhibitor + ribavirin }\end{array}$ & $\begin{array}{l}\text { Ribavirin + peginterferon + protease } \\
\text { Inhibitors; pre-LT polymerase inhibitor + } \\
\text { ribavirin; retransplantation }\end{array}$ \\
\hline HBV infection & $<10 \%(4)$ & $\begin{array}{l}\text { HBsAg and HBV DNA PCR; } \\
\text { liver biopsy }\end{array}$ & $\begin{array}{l}\text { HBIg plus Nucleoside or nucleotide } \\
\text { analogues }\end{array}$ & $\begin{array}{l}\text { Nucleoside or nucleotide analogues; } \\
\text { retransplantation rare }\end{array}$ \\
\hline $\begin{array}{l}\text { Nonalcoholic fatty liver } \\
\text { disease }\end{array}$ & $4 \%$ to $33 \%(5)$ & Ultrasound; liver biopsy & $\begin{array}{l}\text { Lifestyle modifications; treatment of } \\
\text { risk factors; Steroid-free } \\
\text { immunosuppression }\end{array}$ & $\begin{array}{l}\text { Lifestyle modifications; treatment of risk } \\
\text { factors; retransplantation }\end{array}$ \\
\hline Alcoholic liver disease & $<5 \%(6)$ & $\begin{array}{l}\text { History; measurement of } \\
\text { ethanol level }\end{array}$ & $\begin{array}{l}\text { Six months of abstinence before LT; } \\
\text { assessment by addiction } \\
\text { psychiatry; support group }\end{array}$ & $\begin{array}{l}\text { Hospitalization (detoxification, } \\
\text { withdrawal) }\end{array}$ \\
\hline Hemochromatosis & $0 \%(7)$ & $\begin{array}{l}\text { Measurement of ferritin levels } \\
\text { and transferrin saturation; } \\
\text { liver biopsy }\end{array}$ & Regular phlebotomy & Regular phlebotomy \\
\hline $\begin{array}{l}\text { Hepatocellular } \\
\text { carcinoma }\end{array}$ & $\begin{array}{l}\text { Up to } 12.9 \% \text { with sirolimus, } \\
\text { up to } 38.7 \% \text { with CNIs }\end{array}$ & Ultrasound every 6 months & $\begin{array}{l}\text { Sirolimus for high-risk lesions } \\
\text { (retrospective data) (8) }\end{array}$ & $\begin{array}{l}\text { Resection; locoregional therapy } \\
\text { (eg, TACE and RFA, sorafenib) }\end{array}$ \\
\hline Cholangiocarcinoma & $\begin{array}{l}\text { Five-year recurrence-free } \\
\text { survival } 70 \%(9)\end{array}$ & $\begin{array}{l}\text { Ultrasound and/or CT and/or } \\
\text { MRCP/MRI }\end{array}$ & $\begin{array}{l}\text { Possibly mTOR inhibitors (no } \\
\text { evidence for this) }\end{array}$ & Resection, radiation, chemotherapy \\
\hline Autoimmune hepatitis & $20 \%$ to $42 \%(10)$ & Liver biopsy & Consider dual immunosuppression & Glucocorticoids \pm azathioprine or MMF \\
\hline Primary biliary cirrhosis & $16 \%(11)$ & $\begin{array}{l}\text { GGT; AP and bilirubin levels; } \\
\text { liver biopsy }\end{array}$ & - & UDCA; retransplantation \\
\hline $\begin{array}{l}\text { Primary sclerosing } \\
\text { cholangitis }\end{array}$ & $17 \%(11)$ & $\begin{array}{l}\text { GGT; AP and bilirubin levels; } \\
\text { MRCP and/or ERCP and/or } \\
\text { PTC; liver biopsy }\end{array}$ & - & Bile duct dilation; retransplantation \\
\hline
\end{tabular}

Data adapted from reference 54. AFP Alpha-fetoprotein; AP Alkaline phosphatase; CNI Calcineurin inhibitors; CT Computed tomography; ERCP Endoscopic retrograde cholangiopancreatography; GGT Gamma glutamyl transferase; HBlg Hepatitis B immunoglobulin; HBsAg Hepatitis B surface antigen; HBV Hepatitis B virus; MMF Mycophenolate mofetil; MRCP Magnetic resonance cholangiopancreatography; MRI Magnetic resonance imaging; mTOR Mammalian target of rapamycin; PCR Polymerase chain reaction; PTC Percutaneous transhepatic cholangiography; RFA Radiofrequency ablation; TACE Transarterial chemoembolization; TIPS Transjugular intrahepatic portosystemic shunt; UDCA Ursodeoxycholic acid

Over the years, it has come to be recognized that cryptogenic cirrhosis represents burnt-out nonalcoholic steatohepatitis (NASH). The incidence of NASH following LT is on the rise, and can be compounded by the metabolic syndrome to which LT recipients are susceptible (15). Recurrent NASH should be managed by treating the underlying metabolic syndrome. 
TABLE 4

Antihypertensive agents used in liver transplantation

\begin{tabular}{|c|c|c|}
\hline Antihypertensive agent & Benefits & Adverse effects \\
\hline $\begin{array}{l}\text { Calcium channel blockers, dihydropyridine class } \\
\text { (eg, nifedipine) (first-line) }\end{array}$ & Decrease CNI-induced vasoconstriction & Headache, reflux tachycardia, edema, interact with CNIs \\
\hline Beta-blockers & $\begin{array}{l}\text { Decrease } \mathrm{CNI} \text {-induced headache, decreased } \\
\text { left ventricular hypertrophy }\end{array}$ & Impotence, bronchospasm, interact with CNIs \\
\hline $\begin{array}{l}\text { Angiotensin converting enzyme inhibitors and } \\
\text { Angiotensin receptor blockers }\end{array}$ & $\begin{array}{l}\text { Renal-sparing effects in diabetics, decreased } \\
\mathrm{CNI} \text {-induced vasoconstriction }\end{array}$ & $\begin{array}{l}\text { Renal insufficiency and hyperkalemia (more with } \\
\text { combination with CNIs) }\end{array}$ \\
\hline Centrally acting alpha-2-agonists (eg, clonidine) & Decreases $\mathrm{CNI}$-induced renal vasoconstriction & Sedation and depression \\
\hline
\end{tabular}

CNI Calcineurin inhibitor

TABLE 5

Hypoglycemic agents used in liver transplantation

\begin{tabular}{llll}
\hline Hypoglycemic agent & Target population & Advantage(s) & Disadvantages \\
\hline Sulfonylureas & Recent-onset NODAT & Low cost, rapid onset of action & Weight gain, hypoglycemia \\
Metformin & Metabolic syndrome & No weight gain, lower risk of hypoglycemia & GI side effects, lactic acidosis (in CKD) \\
Thiazolidinediones & Metabolic syndrome & Lower risk of hypoglycemia & Weight gain, liver toxicity (rare)
\end{tabular}

Adapted from reference 23. CKD Chronic kidney disease; GI Gastrointestinal; NODAT New-onset diabetes after transplantation

\section{TABLE 6}

Risk factors for the development of renal dysfunction in liver transplantation

\begin{tabular}{ll}
\hline Pretransplant factors & Post-transplant factors \\
\hline Female sex & Postoperative acute kidney injury and \\
Older age at transplant & liver allograft dysfunction \\
Pre-existing chronic kidney disease & Nephrotoxic drugs including \\
Hypertension & calcineurin inhibitors \\
Diabetes & Hypertension \\
Coronary artery disease & Diabetes
\end{tabular}

Hepatitis C virus infection

Adapted from reference 60

Recurrent alcoholism has been reported in up to $20 \%$ of patients transplanted for alcoholic liver disease, with resultant decrease in long-term survival (16). However, the lower risk of recurrent disease is prompting an ethical discussion of appropriate selection of patients for LT. Many factors come into play such as the shortage of organs, optimal organ utilization and ensuring the best possible outcome for recipients. Currently, there is interest in studying and formalizing the indications for LT across Canada.

\section{Metabolic complications following LT}

Hypertension occurs in up to $70 \%$ of patients within the first year post-transplant secondary to CNI and corticosteroid use (17). Evidence-based information regarding optimal antihypertensive pharmacotherapy in LT is limited, although the effect of hypertension on renal function is particularly important. Based on expert opinion, the goal of antihypertensive therapy should be a blood pressure of $140 / 90 \mathrm{mmHg}$, or $130 / 80 \mathrm{mmHg}$ in individuals with additional risk factors for atherosclerotic cardiovascular disease (18). The dihydropyridine class of long-acting calcium channel blockers, including nifedipine and amlodipine, are the first-line antihypertensives because they minimally interact with CNIs (Table 4). Beyond one year after LT, patients may benefit from the use of angiotensin-converting enzyme inhibitors or angiotensin receptor blockers, particularly those who are diabetic or have proteinuria (19).

New-onset diabetes after transplantation (NODAT) occurs in up to $26 \%$ of patients at one year (20). There is a strong association between insulin resistance and diabetes with HCV infection, with up to one-half of HCV-positive LT recipients developing NODAT (21). It is associated with increased cardiovascular morbidity and mortality, development of renal dysfunction, a higher incidence of fatal infections, more rejections and impaired graft survival (22). Screening for NODAT should begin in the immediate post-LT period with regular fasting blood glucose monitoring. As discussed above, treatment goals are similar to those of diabetes in general: prevention of complications such as renal failure, neuropathy, retinopathy, cardiovascular and cerebrovascular disease.

Treatment includes limiting caloric intake, appropriate diet/exercise with weight loss, and initiation of pharmacological agents for treatment of diabetes (Table 5) (23). In addition to steroid withdrawal and reducing $\mathrm{CNI}$ dose, switching from tacrolimus to cyclosporine (a less diabetogenic agent) is often effective (24).

Dyslipidemia affects up to $43 \%$ of patients after LT, and occurs particularly due to CNI use. Sirolimus is associated with an even higher risk of dyslipidemia than CNIs, although this has not translated into an increased incidence of cardiovascular events (25). Lipid profile screening every six months is recommended. Statins are safe and effective in controlling hyperlipidemia without impacting CNI levels (26). Concern regarding hepatotoxicity should not prevent their use, and routine monitoring should be observed. Statin-induced myalgia or myopathy was shown to affect $8.6 \%$ of patients in a retrospective study (27), although it was mild and disappeared with discontinuation of the statin.

Nutritional status is often compromised in patients with ESLD. Following LT, an improved sense of well-being, along with prednisone treatment, contributes to overeating and development of obesity. One cohort study showed that approximately $20 \%$ of nonobese transplant recipients became obese over a two-year follow-up period $(28,29)$. Patients transplanted for NASH tend to develop recurrent hepatic steatosis after LT with weight gain (30). Treatment of obesity involves a balanced diet, aerobic exercise and considering altering immunosuppressive medications, including steroid withdrawal.

Low bone mineral density occurs in up to $70 \%$ of patients with liver disease (31). The use of steroids and CNIs can further precipitate decline in bone mass after LT, reaching a plateau six months postoperatively. Transplant recipients should be screened for metabolic bone disease with dual energy $\mathrm{x}$-ray absorptiometry scan every two years. Preventive strategies, such as physical activity and smoking cessation, should be encouraged. Daily supplementation with $1500 \mathrm{mg}$ of calcium and $800 \mathrm{IU}$ of vitamin D should be given to all patients, along with bisphosphonates and testosterone replacement in hypoandrogenic states as needed.

\section{Renal complications after LT}

Chronic kidney disease (CKD), defined as a glomerular filtration rate (GFR) $<30 \mathrm{~mL} / \mathrm{min} / 1.73 \mathrm{~m}^{2}$ body surface area, occurs in up to $90 \%$ of LT recipients and is multifactorial in etiology (Table 6) (32). The incidence of renal dysfunction has especially increased with the 
TABLE 7

Recommended screening intervals for malignancies for liver transplant patients

\begin{tabular}{ll}
\hline Malignancy & Recommended examination (screening interval, if applicable) \\
\hline Breast cancer & Annual mammography starting at 50 years of age (similar to general population) \\
Cervical cancer & Pelvic examination and Pap smear (similar to general population) \\
Colon cancer & Colonoscopy every 5 to 10 years if no history of colonic neoplasia, every 3 to 5 years with history of neoplasia, yearly in ulcerative colitis patients \\
Esophageal cancer & EGD in patients with Barrett's esophagus and those at high risk for esophageal cancer (smokers and those transplanted for EtOH cirrhosis) \\
Lung cancer & Chest x-ray every 1 to 2 years in smokers and those transplanted for EtOH cirrhosis \\
Oropharyngeal cancer & Otolaryngological examination every 1 to 3 years in smokers and those transplanted for EtOH cirrhosis \\
Prostate cancer & Digital rectal examination and prostate-specific antigen \\
Skin cancer & Annual skin examination
\end{tabular}

EGD Esophagogastroduodenoscopy; EtOH Ethanol

adoption of the Model for End-stage Liver Disease score to prioritize patients for LT, with a $15 \%$ higher risk of post-LT end-stage renal disease $(33,34)$. Based on prospective cohort data, CKD is associated with a 4.5 times greater probability of death versus patients with normal renal function, and a $2 \%$ to $5 \%$ per year risk of requiring dialysis (35). CNIs cause vasoconstriction of the renal afferent arterioles, resulting in decreased renal perfusion. Renal failure due to CNIs may be reversible with dose reduction or medication withdrawal $(10,11)$.

Patients may be switched to the mTOR inhibitors sirolimus and everolimus for immunosuppression to preserve kidney function in the long term after LT. These patients should be screened for development of proteinuria, although its long-term impact on renal function is unclear (36).

\section{Biliary complications}

Biliary complications after LT usually occur as a result of impaired vascular supply at some time point during the patient's postoperative course (37). Bile leaks are the most common, affecting up to $30 \%$ of LT recipients in the early postoperative period. Stricturing at the biliary anastomosis may occur in the long term, which can be reversed with dilation and stenting via endoscopic retrograde cholangiopancreatography (ERCP). In patients who develop hepatic artery thrombosis or have other risk factors with a significant impact on hepatic arterial flow, ischemic cholangiopathy may result in the long term. This condition is often complicated by recurrent cholangitis, and can be treated with antibiotics and stenting, although retransplantation is often indicated. Some patients may have Roux-en-Y anatomy following LT, especially those transplanted for primary sclerosing cholangitis, which will render ERCP more technically challenging (this technical difficulty is due to the length of the Roux limb, which may be circumvented by performing ERCP assisted by double-balloon technique at certain Canadian centres with this expertise).

\section{SCREENING FOR MALIGNANCIES AFTER TRANSPLANT}

Transplant patients are at higher risk for developing malignancies because immunosuppression curtails the cancer-sensing function of the immune system (38). Improving patient survival has resulted in exposure to immunosuppression for an extended period; consequently, nonskin malignancies arise in up to $16 \%$ of recipients and represent a common cause of late deaths. This is especially true in patients with concurrent smoking and alcohol use, who should undergo annual endoscopy, laryngoscopy and chest-x-ray, as described in Table 7. Skin cancers are up to 100 times more common among LT recipients compared with the general population (25). Transplant recipients should avoid excessive sun exposure, apply sunscreen regularly and undergo a thorough dermatological examination annually. Post-transplant lymphoproliferative disorder (PTLD) is associated with Epstein-Barr virus infection in $90 \%$ of cases and occurs in up to $2 \%$ of LT patients within the first year (39). Overall, PTLD has been known to affect up to $2.8 \%$ of adult and up to $15 \%$ of pediatric LT recipients (40). This generally presents as fevers, night sweats, weight loss and malaise, with or without lymphadenopathy. PTLD is managed through reduction of immunosuppression, rituximab or chemotherapy. Colonoscopy for colorectal cancer screening should be performed every five years, and annually if patient has a diagnosis of primary sclerosing cholangitis with ulcerative colitis. All other malignancies are screened as per recommendations for the general population.

\section{PREVENTIVE CARE, QUALITY OF LIFE, SEXUALITY AND PREGNANCY}

Potential LT recipients should ideally receive all necessary vaccinations before transplant because immunosuppressants significantly suppress $\mathrm{T}$ cell function and increase risk for infection (41). Liveattenuated vaccines carry a potential risk of shedding live virus, although studies have confirmed that these can be safely given to transplant patients $(42,43)$. Any administration of live-attenuated vaccines such as varicella, Bacillus Calmette-Guérin, measles-mumpsrubella, polio, typhoid, yellow fever and rotavirus, should be performed only in consultation with the transplant centre. Only the following vaccines may be safely administered to both $\mathrm{LT}$ recipients and their household contacts: hepatitis A, hepatitis B, inactivated influenza, meningococcal, pneumococcal, tetanus, diphtheria, Haemophilus influenzae type $b$, pertussis and human papilloma virus.

Transplant recipients who smoke should be counselled regarding smoking cessation because the adverse effects of tobacco are possibly heightened. Studies have shown that LT recipients who smoke are at increased risk for all-cause mortality and vascular events (coronary artery disease, stroke and hepatic artery thrombosis, which can lead to graft loss). Nicotine replacement therapy and medications, such as bupropion, can safely be offered. Cannabis should be discouraged because it is known to worsen hepatic steatosis and fibrosis in chronic liver disease patients $(44,45)$. Proper dental hygiene and regular check-ups are essential because excess oral bacteria in the presence of immunosuppression can lead to development of serious infections such as infective endocarditis. Antibiotic prophylaxis is not required in the transplant patient population, even in the context of dental procedures, unless an underlying cardiac condition predisposing to endocarditis is present.

ESLD causes significant disability, to the point of being unable to perform activities of daily living. LT enables the return of most patients to the workforce, which greatly enhances daily activities, physical health, health-related quality of life, sexual function and psychosocial well-being (46). Recipients may not have a health-related quality of life equivalent to that of the general population because many are readmitted to hospital for complications such as impaired wound healing and infections. However, resources, such as a dedicated transplant nurse, an exercise program and psychosocial support, can help improve perception of health and quality of life (47).

The availability of psychological support is important because reactive depression can occur due to difficulty coping with post-transplant life. Occupational counselling should be offered if a patient is experiencing difficulties in returning to the workforce. A Canadian transplant centre determined that $57 \%$ of their patients surviving a minimum of nine months had returned to employment (48). 
A majority of patients with ESLD lose sexual function and fertility (49). With LT, sexual function returns to normal in $>90 \%$ of recipients (50). Erectile dysfunction may be treated with standard medications. Fertility could return at any time after transplantation; therefore, contraception should be used on resumption of sexual activity. Ideally, pregnancy should be delayed beyond the one-year mark after LT. The use of MMF in pregnant mothers has been associated with birth defects and miscarriages. MMF should either be avoided among women of reproductive age or should be discontinued at least six weeks before a planned conception. A live birth rate $>70 \%$ with favourable maternal and fetal outcomes has been documented in the American National Transplantation Pregnancy Registry (51). During pregnancy, hypertension is a complication encountered in up to $45 \%$ of transplant recipients (49). An increase in plasma protein levels that bind cyclosporine and tacrolimus can lead to subtherapeutic levels. Pregnancy is, therefore, associated with a $10 \%$ risk of organ rejection and requires more frequent monitoring of immunosuppressant levels to maintain the therapeutic range (52). Prematurity and low birth weight are the

\section{REFERENCES}

1. McGuire B, Rosenthal P, Brown C, et al. Long term management of the liver transplant patient: Recommendations for the primary care doctor. Am J Transpl 2009;9:1988-2003.

2. Register COR. 2013 Canadian Organ Replacement Register (CORR) report-Treatment of end-stage organ failure report, 2002 to 2011, 2013.

3. Roberts MS, Angus DC, Bryce CL, Valenta Z, Weissfeld L. Survival after liver transplantation in the United States: A disease specific analysis of the UNOS database. Liver Transpl 2004;10:886-97.

4. Meier-Kriesche HU, Li S, Gruessner RW, et al. Immunosuppression: Evolution in practice and trends, 1994-2004. Am J Transpl 2006;6(5 Pt 2):1111-31.

5. Playford E, Webster A, Sorell T, Craig J. Antifungal agents for preventing fungal infections in solid organ transplant recipients. Cochrane Database Syst Rev (Online) 2004(3):CD004291.

6. Hodson E, Craig J, Strippoli G, Webster A. Antiviral medications for preventing cytomegalovirus disease in solid organ transplant recipients. Cochrane Database Syst Rev (Online) 2008(2):CD003774.

7. Berenguer M, Prieto M, Rayon JM, et al. Natural history of clinically compensated hepatitis $\mathrm{C}$ virus-related graft cirrhosis after liver transplantation. Hepatology 2000;32(4 Pt 1):852-8.

8. Coilly A, Roche B, Dumortier J, et al. Safety and efficacy of protease inhibitors to treat hepatitis $\mathrm{C}$ after liver transplantation: A multicenter experience. J Hepatol 2014;60:78-86.

9. Zeuzem S, Berg T, Gane E, et al. Simeprevir Increases Rate of Sustained Virologic Response Among Treatment-Experienced Patients With HCV Genotype-1 Infection: A Phase IIb Trial. Gastroenterology November 2013 (E-pub ahead of print).

10. Charlton MR, Gane EJ, Manns MP, et al. Sofosbuvir and Ribavirin for the Treatment of Established Recurrent Hepatitis C Infection After Liver Transplantation: Preliminary results of a prospective, multicenter study. 64th Annual Meeting of the American Association for the Study of Liver Diseases (AASLD 2013). Washington, DC, November 1 to 5, 2013. Abstract LB-2.

11. Fung J, Chan SC, Cheung C, et al. Oral nucleoside/nucleotide analogs without hepatitis B immune globulin after liver transplantation for hepatitis B. Am J Gastroenterol 2013;108:942-8.

12. Darwish Murad S, Kim WR, et al. Predictors of pretransplant dropout and posttransplant recurrence in patients with perihilar cholangiocarcinoma. Hepatology 2012;56:972-81.

13. Menon KV, Hakeem AR, Heaton ND. Meta-analysis: Recurrence and survival following the use of sirolimus in liver transplantation for hepatocellular carcinoma. Aliment Pharmacol Ther 2013;37:411-9.

14. Mancuso A, Mazzarelli C, Perricone G, Zavaglia C. Sorafenib efficacy for treatment of HCC recurrence after liver transplantation is an open issue. J Hepatol November 2013 (E-pub ahead of print).

15. Patil DT, Yerian LM. Evolution of nonalcoholic fatty liver disease recurrence after liver transplantation. Liver Transpl 2012;18:1147-53.

16. Pfitzmann R, Schwenzer J, Rayes N, Seehofer D, Neuhaus R, Nussler NC. Long-term survival and predictors of relapse after orthotopic liver transplantation for alcoholic liver disease. Liver Transpl 2007;13:197-205. most common fetal complications, occurring in 10\% to $55 \%$ of pregnancies (53). Overall, the long-term outcomes of most babies exposed to immunosuppressants in utero is favourable, with normal development (51).

\section{CONCLUSION}

The care of LT recipients has evolved, with excellent survival rates following LT. Gastroenterologists and primary care physicians in the community often follow LT recipients in conjunction with the LT physician, and it is important to be aware of the unique medical needs and complications associated with long-term immunosuppression. Such comprehensive care will ensure that the LT recipient benefits from optimal health and quality of life.

DISCLOSURES: The authors have no financial disclosures or conflicts of interest to declare.
17. Sheiner PA, Magliocca JF, Bodian CA, et al. Long-term medical complications in patients surviving $>$ or $=5$ years after liver transplant. Transplantation 2000;69:781-9.

18. Munoz SJ, Elgenaidi H. Cardiovascular risk factors after liver transplantation. Liver Transpl 2005(11 Suppl 2):S52-6.

19. Najeed SA, Saghir S, Hein B, et al. Management of hypertension in liver transplant patients. Int J Cardiol 2011;152:4-6.

20. Navasa M, Bustamante J, Marroni C, et al. Diabetes mellitus after liver transplantation: Prevalence and predictive factors. J Hepatol 1996;25:64-71.

21. Gane EJ. Diabetes mellitus following liver transplantation in patients with hepatitis $\mathrm{C}$ virus: Risks and consequences. Am J Transpl 2012;12:531-8.

22. Moon JI, Barbeito R, Faradji RN, Gaynor JJ, Tzakis AG. Negative impact of new-onset diabetes mellitus on patient and graft survival after liver transplantation: Long-term follow up. Transplantation 2006;82:1625-8.

23. Davidson JA, Wilkinson A. New-onset diabetes after transplantation 2003 International Consensus Guidelines: An endocrinologist's view. Diabetes Care 2004;27:805-12.

24. Yoshida EM, Lilly LB, Marotta PJ, Mason AL, Bilodeau M, Vaillancourt M. Canadian national retrospective chart review comparing the long term effect of cyclosporine vs. tacrolimus on clinical outcomes in patients with post-liver transplantation hepatitis C virus infection. Ann Hepatol 2013;12:282-93.

25. Chinnakotla S, Davis GL, Vasani S, et al. Impact of sirolimus on the recurrence of hepatocellular carcinoma after liver transplantation. Liver Transpl 2009;15:1834-42.

26. Gazi IF, Liberopoulos EN, Athyros VG, Elisaf M, Mikhailidis DP. Statins and solid organ transplantation. Curr Pharm Des 2006;12:4771-83.

27. Martin JE, Cavanaugh TM, Trumbull L, et al. Incidence of adverse events with HMG-CoA reductase inhibitors in liver transplant patients. Clin Transpl 2008;22:113-9.

28. Everhart JE, Lombardero M, Lake JR, Wiesner RH, Zetterman RK, Hoofnagle JH. Weight change and obesity after liver transplantation: Incidence and risk factors. Liver Transpl Surg 1998;4:285-96.

29. Canzanello VJ, Schwartz L, Taler SJ, et al. Evolution of cardiovascular risk after liver transplantation: A comparison of cyclosporine A and tacrolimus (FK506). Liver Transpl Surg 1997;3:1-9.

30. Contos MJ, Cales W, Sterling RK, et al. Development of nonalcoholic fatty liver disease after orthotopic liver transplantation for cryptogenic cirrhosis. Liver Transpl 2001;7:363-73.

31. Neuhaus R, Lohmann R, Platz KP, et al. Treatment of osteoporosis after liver transplantation. Transplant Proc 1995;27:1226-7.

32. K/DOQI clinical practice guidelines for chronic kidney disease: Evaluation, classification, and stratification. Am J Kidney Dis 2002;39(2 Suppl 1):S1-266.

33. Sharma P, Schaubel DE, Guidinger MK, Goodrich NP, Ojo AO, Merion RM. Impact of MELD-based allocation on end-stage renal disease after liver transplantation. Am J Transpl 2011;11:2372-8. 
34. Myers RP, Shaheen AA, Aspinall AI, Quinn RR, Burak KW. Gender, renal function, and outcomes on the liver transplant waiting list: Assessment of revised MELD including estimated glomerular filtration rate. J Hepatol 2011;54:462-70.

35. Ojo AO. Scope of the problem and impact on outcomes. Liver Transpl 2009;15(Suppl 2):S1.

36. Letavernier E, Pe'raldi MN, Pariente A, Morelon E, Legendre C. Proteinuria following a switch from calcineurin inhibitors to sirolimus. Transplantation 2005;80:1198-203.

37. Seehofer D, Eurich D, Veltzke-Schlieker W, Neuhaus P. Biliary complications after liver transplantation: Old problems and new challenges. Am J Transpl 2013;13:253-65.

38. Ulrich C, Schmook T, Sachse MM, Sterry W, Stockfleth E. Comparative epidemiology and pathogenic factors for nonmelanoma skin cancer in organ transplant patients. Dermatol Surg 2004;30(4p2):622-27.

39. Nalesnik MA, Starzl TE. Epstein-Barr virus, infectious mononucleosis, and posttransplant lymphoproliferative disorders. Transpl Sci 1994;4:61.

40. Taylor AL, Marcus R, Bradley JA. Post-transplant lymphoproliferative disorders (PTLD) after solid organ transplantation. Crit Rev Oncol Hematol 2005;56:155-67.

41. Zeldin GA, Maygers J, Klein A, Thuluvath PJ. Vaccination, screening for malignancy, and health maintenance of the liver transplant recipient. J Clin Gastroenterol 2001;32:148.

42. Kano H, Mizuta K, Sakakihara Y, et al. Efficacy and safety of immunization for pre-and post-liver transplant children. Transplantation 2002;74:543.

43. Khan S, Erlichman J, Rand EB. Live virus immunization after orthotopic liver transplantation. Pediatr Transpl 2006;10:78-82.

44. Missiha SB, Ostrowski M, Heathcote EJ. Disease progression in chronic hepatitis C: Modifiable and nonmodifiable factors. Gastroenterology 2008;134:1699-714.

45. Hézode C, Roudot Thoraval F, et al. Daily cannabis smoking as a risk factor for progression of fibrosis in chronic hepatitis $\mathrm{C}$. Hepatology 2005;42:63-71.

46. Saab S, Wiese C, Ibrahim AB, et al. Employment and quality of life in liver transplant recipients. Liver Transpl 2007;13:1330-8.
47. Hunt CM, Tart JS, Dowdy E, Bute BP, Williams DM, Clavien PA. Effect of orthotopic liver transplantation on employment and health status. Liver Transpl 1996;2:148-53.

48. Adams PC, Ghent CN, Grant DR, Wall WJ. Employment after liver transplantation. Hepatology 1995;21:140-44.

49. Armenti VT, Herrine SK, Radomski JS, Moritz MJ. Pregnancy after liver transplantation. Liver Transpl 2000;6:671-85.

50. Ho JK, Ko HH, Schaeffer DF, et al. Sexual health after orthotopic liver transplantation. Liver Transpl 2006;12:1478-84.

51. Coscia LA, Constantinescu S, Moritz MJ, et al. Report from the National Transplantation Pregnancy Registry (NTPR): Outcomes of pregnancy after transplantation. Clin Transpl 2008:89.

52. Cardonick E, Moritz M, Armenti V. Pregnancy in patients with organ transplantation: A review. Obstet Gynecological Survey 2004:59:214.

53. Nagy S, Bush MC, Berkowitz R, Fishbein TM, Gomez-Lobo V. Pregnancy outcome in liver transplant recipients. Obstet Gynecol 2003;102:121.

54. Benten D, Staufer K, Sterneck M. Orthotopic liver transplantation and what to do during follow-up: Recommendations for the practitioner. Nat Clin Pract Gastroenterol Hepatol 2009;6:23-36.

55. Johnson SR, Alexopoulos S, Curry M, Hanto DW. Primary nonfunction (PNF) in the MELD era: An SRTR database analysis. Am J Transpl 2007; 7:1003-9.

56. Singal AK, Chaha KS, Rasheed K, Anand BS. Liver transplantation in alcoholic liver disease current status and controversies. World J Gastroenterol 2013;19:5953-63.

57. Crawford DH, Fletcher LM, Hubscher SG, et al. Patient and graft survival after liver transplantation for hereditary hemochromatosis: Implications for pathogenesis. Hepatology 2004;39:1655-62.

58. Molmenti EP, Netto GJ, Murray NG, et al. Incidence and recurrence of autoimmune/alloimmune hepatitis in liver transplant recipients. Liver Transpl 2002;8:519-26.

59. Gautam M, Cheruvattath R, Balan V. Recurrence of autoimmune liver disease after liver transplantation: A systematic review. Liver Transpl 2006;12:1813-24.

60. Ojo AO, Held PJ, Port FK, et al. Chronic renal failure after transplantation of a nonrenal organ. N Engl J Med 2003;349:931-40. 


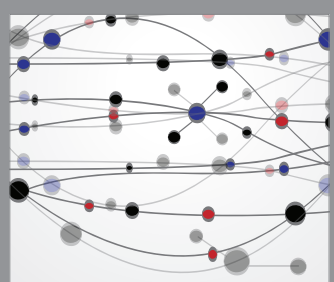

The Scientific World Journal
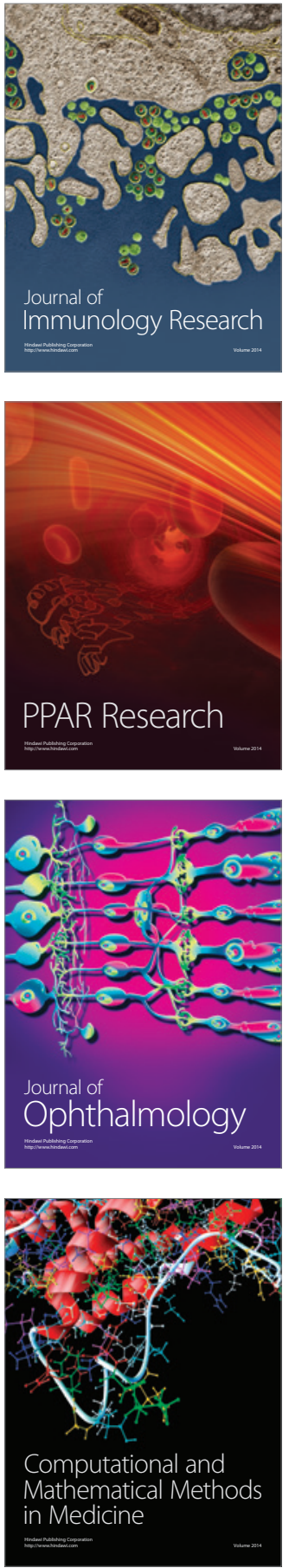

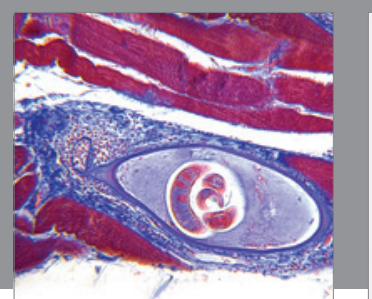

Gastroenterology Research and Practice

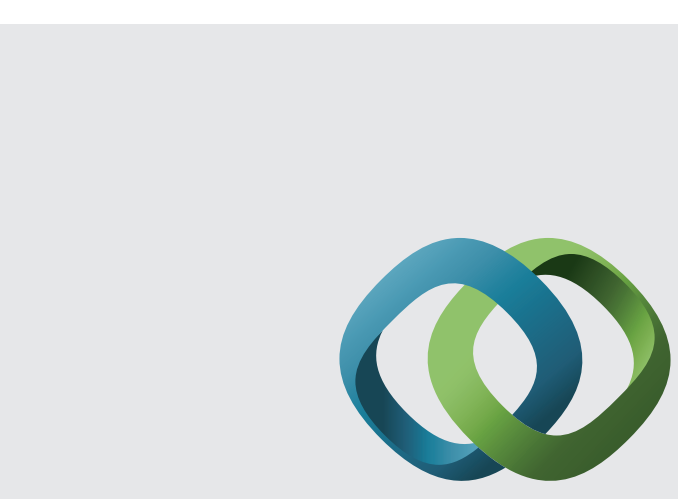

\section{Hindawi}

Submit your manuscripts at

http://www.hindawi.com
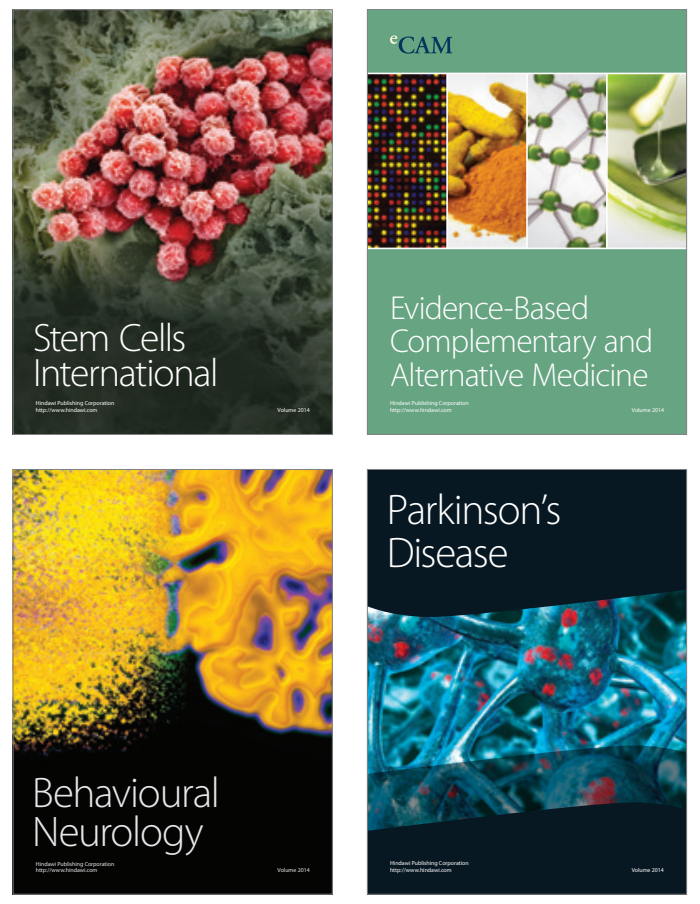
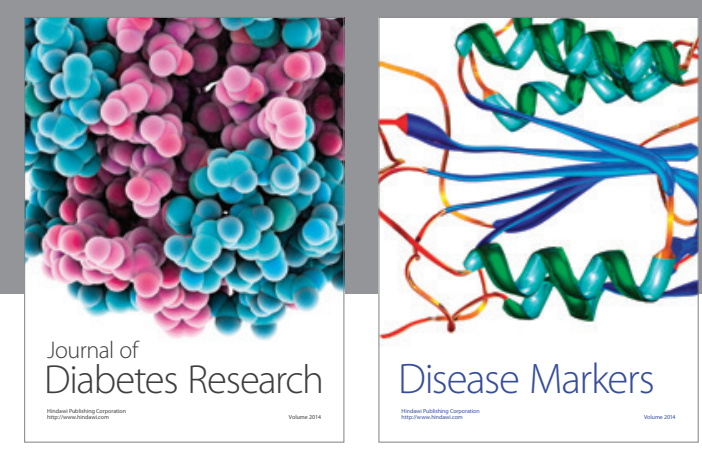

Disease Markers
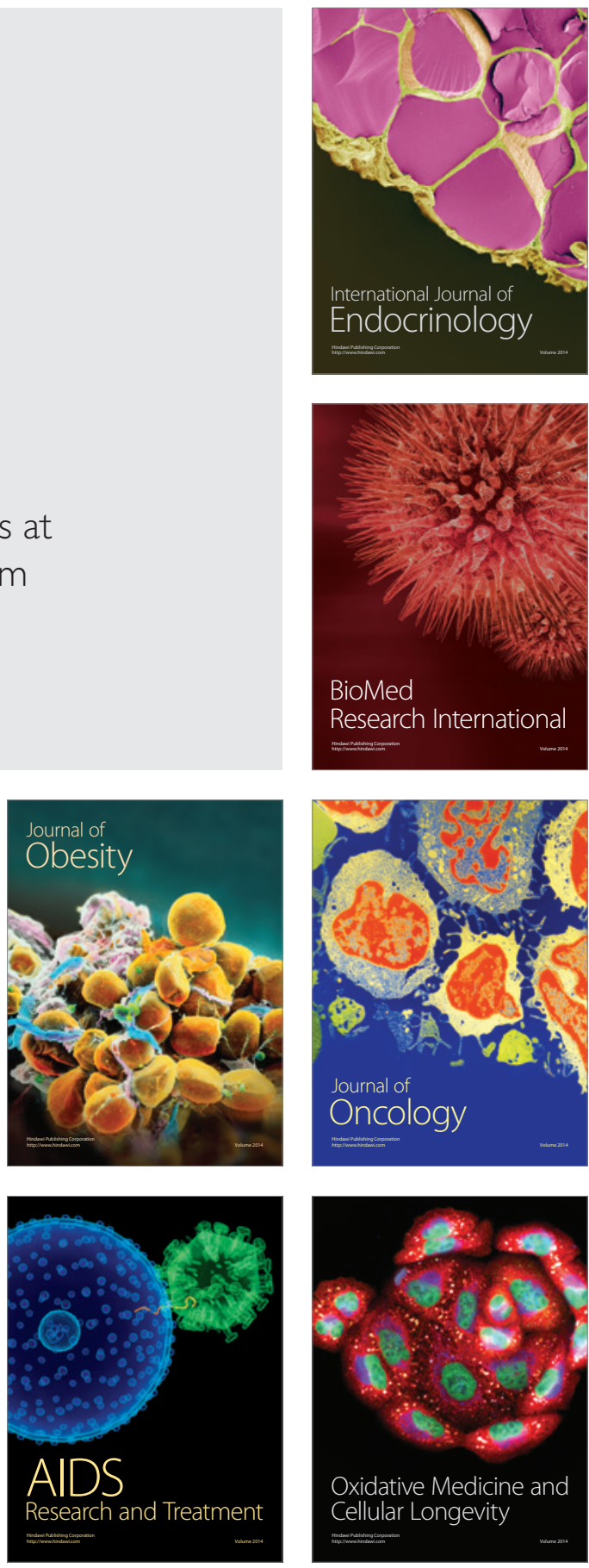